\title{
A $10 \mathrm{GHz}$ Y-Ba-Cu-O/GaAs Hybrid Oscillator Proximity Coupled to a Circular Microstrip Patch Antenna
}

\author{
Norman J. Rohrer, M. A. Richard, Student Member, IEEE, George J. Valco, Member, IEEE, and \\ Kul B. Bhasin, Senior Member, IEEE
}

\begin{abstract}
A $10 \mathrm{GHz}$ hybrid Y-Ba-Cu-O/GaAs microwave oscillator proximity coupled to a circular microstrip antenna has been designed, fabricated and characterized. The oscillator was a reflection mode type using a GaAs MESFET as the active element. The feedline, Iransmission lines, if chokes, and bias lines were all fabricated from $\mathrm{YBa}_{2} \mathrm{Cu}_{3} \mathrm{O}_{7-x}$ superconducting thin films on a $1 \mathrm{~cm} \times 1 \mathrm{~cm}$ lanthanum aluminate substrate. The output feedline of the oscillator was wire bonded to a superconducting feedline on a second $1 \mathrm{~cm} \times 1 \mathrm{~cm}$ lanthanum aluminate substrate, which was in turn proximity coupled to a circular microstrip patch antenna. Antenna patterns from this active patch antenna and the performance of the oscillator measured at $77 \mathrm{~K}$ are reported. The oscillator had a maximum output power of $11.5 \mathrm{dBm}$ at $77 \mathrm{~K}$, which corresponded to an efficiency of $10 \%$. In addition, the efficiency of the microstrip patch antenna together with its high temperature superconducting feedline was measured from $85 \mathrm{~K}$ to $30 \mathrm{~K}$ and was found to be $71 \%$ at $77 \mathrm{~K}$, increasing to a maximum of $87.4 \%$ at $30 \mathrm{~K}$.
\end{abstract}

\section{INTRODUCTION}

The application of high temperature superconducting (HTS) thin films to microwave circuits is advantageous since the films have a lower surface resistance than gold or copper at microwave frequencies. Passive circuits such as ring resonators [1], [2], filters [3], transmission lines [4], and antennas [5] fabricated from HTS films have shown substantial improvements in performance over identical circuits fabricated with normal metals. Several authors have suggested that HTS technology may be very beneficial in phase-array antenna systems [6], [7]. To date, a limited amount of work in the area of passive microstrip antennas has been reported [5]. However, for HTS to be useful in phased array antennas, active circuits such as oscillators, phase shifters and power amplifiers, will need to be integrated with radiating elements so that beam control and/or scanning may be realized. Because of the limited amount of available space in high frequency arrays, some authors have suggested the use of an active

Manuscript received August 17, 1992; November 23, 1992. This work was supported by the National Aeronautics and Space Administration under award no. NCC-3-197. M. A. Richard was supported through the Ohio Aerospace Institute Doctoral Fellowship.

N. J. Rohrer and G. J. Valco are with the Department of Electrical Engineering, The Ohio State University, Columbus, OH 43210.

M. A. Richard is with the Department of Electrical Engincering, Case Western Reserve University, Cleveland, $\mathrm{OH} 44106$.

K. B. Bhasin is with the National Aeronautics and Space Administration, Lewis Research Center. Cleveland, OH 44135.

IEEE Log Number 92066?9. patch antenna as the radiating element. By using active patch antennas, the problem of if distribution to each radiating element is minimized and space is made available for phase shifters and power amplifiers.

In this paper, we report a first demonstration of a HTS/GaAs hybrid active patch antenna consisting of a hybrid oscillator on one substrate, and a feedline proximity coupled to a circular microstrip patch antenna on a second substrate. The patch antenna was printed on alumina $\left(\epsilon_{r}=9.9\right)$ to reduce the effective permittivity seen by the radiator. The performance of this active antenna was measured at $77 \mathrm{~K}$.

\section{DESIGN}

Since our objective was to implement the entire oscillator on a single substrate to be cooled to $77 \mathrm{~K}$, the $S$-parameters of the transistors were first obtained by measurements at cryogenic temperatures for use in the design of the oscillator. The active device used in the oscillator was a low noise MESFET with a gate length of $0.25 \mu \mathrm{m}$ (Toshiba GaAs MESFET, part no. JS8830-AS). The $S$-parameters of the FET for the frequency range of $2 \mathrm{GHz}$ to $26 \mathrm{GHz}$ were measured over a range from room temperature $(300 \mathrm{~K})$ to $40 \mathrm{~K}$. The magnitude and angle of the $S$-parameters at $10 \mathrm{GHz}$ as a function of temperature are shown in Fig. 1 . The $S$-parameters as a function of frequency at 300 and $77 \mathrm{~K}$ will be presented elsewhere [8]. Of the $S$-parameters, the largest change in magnitude as a function of temperature occurred for the $S_{21}$ values. This was due to an increase in the electron's mobility at the reduced temperatures. The variation in phase of $S_{11}$ and $S_{22}$ was the only other major change. The percent change of the magnitude and phase of the $S$-parameters at the design frequency of $10 \mathrm{GHz}$ due to the change in the temperature from $300 \mathrm{~K}$ to $77 \mathrm{~K}$ is listed in Table $\mathrm{I}$.

The oscillator was designed using simulations performed with a commercially available software package (Touchstone) under the assumption that the drain current would be held at $I_{d}=10 \mathrm{~mA}$, and that the temperature would be held at $77 \mathrm{~K}$. The design used a parallel coupled ring resonator in the matching network off the drain for the frequency stabilization. Using the small signal $S$ parameters that were measured at $77 \mathrm{~K}$, the input reflection coefficient at the drain was made very large by

(C) 1993 IEEE. Reprinted, with permission, from IEEE Transactions on Applied Superconductivity, vol. 3, no. 1, Mar. 1993, pp. 23-27. 


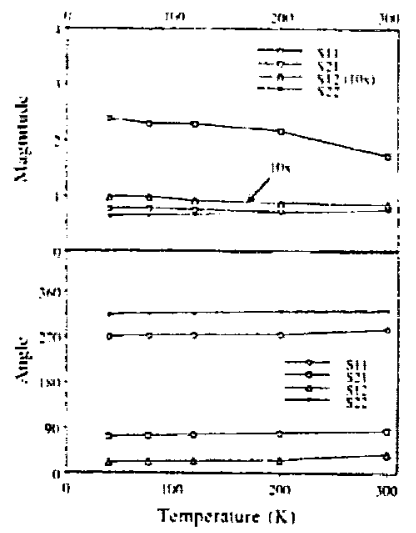

Fig. 1. Magnitude and angle of the $S$-parameters of the GaAsFET at $10 \mathrm{GHz}$ as a function of temperature. The magnitude of $S_{12}$ has been magnified by a factor of 10 for clarity.

TABLE I

Percent Change of THE $S$-Parameters from $300 \mathrm{~K}$ TO $77 \mathrm{~K}$ AT $10 \mathrm{GHz}$

\begin{tabular}{cccccccc}
\hline \multicolumn{2}{c}{$S_{11}$} & \multicolumn{2}{c}{$S_{21}$} & \multicolumn{2}{c}{$S_{12}$} & \multicolumn{2}{c}{$S_{22}$} \\
Magnitude & Phase Magnitude & Phase Magnitude & Phase Magnitude Phase \\
\hline $3.4 \%$ & $16.2 \%$ & $25.6 \%$ & $8.4 \%$ & $4.8 \%$ & $6.2 \%$ & $26.7 \%$ & $27.1 \%$ \\
\hline
\end{tabular}

varying the length of the transmission lines on the source and the gate. The selected lengths of the transmission lines from the source and gate were $1.57 \mathrm{~mm}$ and 2.79 $\mathrm{mm}$, respectively. Both were open circuited lines. The ring resonator, with a fundamental resonant frequency of 10 $\mathrm{GHz}$, which was used to select the frequency of operation was place $\lambda_{g} / 4$ from the drain of the transistor, parallel coupled to the output transmission line using a $40-\mu \mathrm{m}$ wide coupling gap. The matching network, including the ring resonator, was designed such that the magnitude of the real part of the impedance of the matching network was less than the magnitude of the real part of the impedance looking into the drain of the FET. The magnitude of the imaginary part of the impedance was equal to zero at the resonant frequency. With this criterion met, the $10-\mathrm{GHz}$ oscillation will start upon proper biasing of the FET. The output of the oscillator was taken off the drain. The physical layout of this reflection mode oscillator is shown in Fig. 2.

The antenna used for this investigation was a circular microstrip patch which was proximity coupled to a microstrip fecdline. The feedline for the antenna was patterned on a second substrate for two reasons: this method allowed for the testing of both the oscillator and the antenna separately to determine their performance, and secondly, a HTS thin film with an area large enough to pattern the entire circuit was available.

The resonant frequency of the circular antenna patch was found from the formula [9]:

$$
f=\frac{1.841 c}{2 \pi a_{e} \sqrt{\epsilon_{\mathrm{eq}}}}
$$

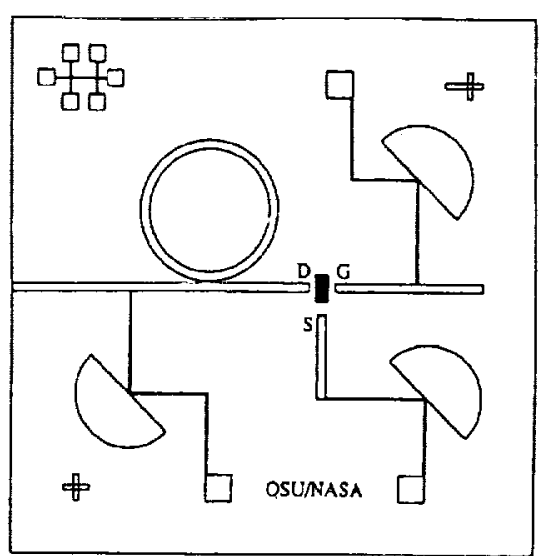

Fig. 2. Physical layout of the hybrid $10 \mathrm{GHz}$ superconductor/GaAs oscillator designed using the reflection method.

where $a_{e}$ is the effective radius of the patch

$$
\begin{aligned}
a_{e}=a\left[1+\frac{2 d}{\pi a \epsilon_{\mathrm{eq}}}\left(\ln \frac{a}{2 d}\right.\right. & +\left(1.41 \epsilon_{\mathrm{eq}}+1.77\right) \\
& \left.\left.+\frac{d}{a}\left(0.268 \epsilon_{\mathrm{eq}}+1.65\right)\right)\right]^{1 / 2}
\end{aligned}
$$

Here, $d$ is sum of the thickness of the two substrates between the patch and the ground plane and $a$ is the physical radius of the patch. Because the patch was printed on an alumina $\left(\epsilon_{1}=9.9\right)$ substrate with a thickness of 254 $\mu \mathrm{m}$ while the feedline and ground plane were on lanthanum aluminate $\left(\epsilon_{2}=23\right)$ with a thickness of $508 \mu \mathrm{m}$, the value for the net $\epsilon_{\mathrm{eq}}$ of this dual layer substrate to use in (1) and (2) was found using a static capacitor model

$$
\epsilon_{\mathrm{eq}}=\frac{3 \epsilon_{1} \epsilon_{2}}{2 \epsilon_{1}+\epsilon_{2}}
$$

to be 16.0 , resulting in the diameter of the patch equaling $4.02 \mathrm{~mm}$. Measurements showed that a slightly larger diamcter of $4.71 \mathrm{~mm}$ resulted in a resonance closer to the desired frequency of $10 \mathrm{GHz}$. The resonant frequency of the patch was tuned to match the output frequency of the oscillator by adjusting the position of the patch over the feedline.

\section{EXPERIMENTAL DETAILS}

An HTS film was patterned into the oscillator using standard positive photolithographic techniques and etched with an aqueous solution of deionized water: $\mathrm{H}_{3} \mathrm{PO}_{4}:: 100: 1$. This film was a commercially purchased film deposited using an off-axis sputtering technique and had a critical temperature of $88.6 \mathrm{~K}$ after patterning. Contacts to the superconductor for the if output and wire bonding pads were made of silver with a gold overlayer patterned by lift-off photolithography. Wire bonding pads were located at the bias pads as well as at the ends of the transmission lines near the FET. The GaAs FET was epoxied onto the substrate and wire bonds were made to 
the transmission lines with 0.7 mil gold wire by thermosonic bonding. A copper ground plane with a thickness of $2.4 \mu \mathrm{m}$ was deposited on the backside of the substrate.

A second HTS thin film was used for the antenna feedline. $\mathrm{A} \mathrm{YBa}_{2} \mathrm{Cu}_{3} \mathrm{O}_{7-x}$ thin film was deposited by pulsed laser deposition onto this substrate [10]. The film had a critical temperature of $86 \mathrm{~K}$. This film was patterned in the same way as the oscillator into a $50 \mathrm{ohm}$ transmission line that was $160 \mu \mathrm{m}$ wide and $5 \mathrm{~mm}$ in length. A silver/gold contact was deposited at the end of the feedline for ribbon bonding, and a $2-\mu \mathrm{m}$ copper ground plane was evaporated on the backside of the substrate. An alumina substrate with the pattined antenna patch was placed on top of the feedline and held in place with small amounts of fingernail polish at the edges.

The performance of the oscillator was measured on a spectrum analyzer at $77 \mathrm{~K}$ by mounting the circuit in a sealed brass test fixture and submerging the fixture in liquid nitrogen. Details of the procedures used for measurement will be presented elsewhere [8]. The antenna with its HTS feedline was measured by placing the circuit on a copper test fixture and mounting the fixture on the second stage of a closed cycle gas refrigerator. A high density polyethylene radome served as a vacuum chamber. Details of the experimental apparatus and procedures have been presented el ewhere [5].

The efficiency of the antenna together with its HTS feedline was measured using the Wheeler Cap method [11]. To do this, the input impedance of the antenna at resonance was measured with and without a radiation shield from $30 \mathrm{~K}$ up to $85 \mathrm{~K}$. The efficiency $(\eta)$ was then calculated as:

$$
\eta=1-\frac{R_{w}}{R_{w o}}
$$

where $R_{w}$ and $R_{w o}$ are the input resistances with and without the radiation shield, respectively. For this work, an aluminum cap with an inner dimension of $12-\mathrm{mm}$ wide $\times 12-\mathrm{mm}$ deep by $6.8 \mathrm{~mm}$ high was used as the radiation shield. Electrical contact to the test fixture was ensured with silver paint.

The oscillator and antenna circuits were then mounted with silver paint onto a brass test fixture. The rf connection between the two substrates was made by ribbon bonding to the contacts on the feedline of antenna and the output of the oscillator (Fig. 3). The test fixture was then mounted in the closed-cycle gas refrigerator and covered with the high density polyethylene radome. An $\mathrm{X}$-band horn attached to a pivoting arm served as the receive antenna to measure the radiation pattern of the active patch antenna in the far field as a function of angle.

\section{Results aivd Discussion}

The output power and frequency of operation of the hybrid oscillator were measured to verify its performance before bonding the oscillator to the antenna circuit. The maximum power attainable from the oscillator at $77 \mathrm{~K}$

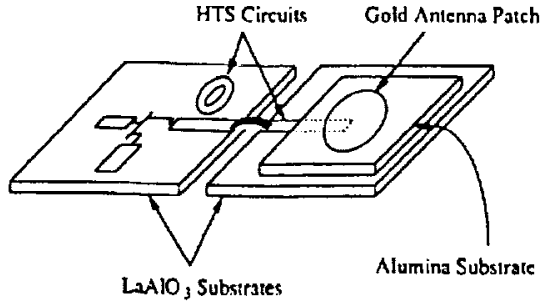

Fig. 3. Physical layout of the active antenna. The gold patch was on an alumina substrate place over a superconducting feedline on a $\mathrm{LaAlO}_{3}$ substrate. The oscillator and patch antenna were ribbon bonded together.

was $11.5 \mathrm{dBm}$ at a bias of $V_{d s}=4.0 \mathrm{~V}$ and $V_{g s}=0.0 \mathrm{~V}$. The sensitivity of the frequency to temperature was -10 $\mathrm{MHz} / \mathrm{K}$ at $77 \mathrm{~K}$. Detailed results of the measurements performed on this oscillator as a function of temperature and bias will be presented elsewhere [8]. For the active antenna measurements at $77 \mathrm{~K}$, the FET was biased at $V_{d s}=0.5 \mathrm{~V}$ and $V_{g s}=-0.5 \mathrm{~V}$ which gave a current of $I_{d}=12 \mathrm{~mA}$. For this bias condition, the frequency of the signal was $10.082 \mathrm{GHz}$ with an output power of -2.0 $\mathrm{dBm}$. The efficiency of the oscillator was $10.5 \%$. The power of the second harmonic at $20.16 \mathrm{GHz}$ was $35 \mathrm{~dB}$ less than the fundamental signal at $77 \mathrm{~K}$.

The efficiency of the antenna was measured before bonding the antenna to the oscillator circuit. The efficiency as a function of temperature is shown in Fig. 4. As expected, the efficiency rises dramatically as the HTS film becomes superconducting and then increases slowly as the temperature decreases, due to the increase in the conductivity of the HTS feedline. This trend was in agreement with the measured performance of HTS ring resonators. The efficiency reaches a maximum of $87.4 \%$ at $30 \mathrm{~K}$.

The measured antenna patterns with the superconducting oscillator driving the antenna are shown in Fig. 5, along with the patterns predicted for the co-polarization by the cavity model [12]. The $H$-plane shows good agreement with the model, while the $E$-plane deviates substantially due to surface waves and the feedline, neither of which are accounted for in the model used. This is in agreement with results published by Schaubert et al. [13] which demonstrated that antennas on high permittivity substrates are characterized by perturbations in the $E$ plane pattern. The $12 \mathrm{~dB}$ dip in the $E$-plane and the cross polarization patterns at an angle of 15 degrees was almost certainly due to radiation interference from the resonator and microstrip lines on the oscillator.

\section{CONCLUSION}

The performance of a $10 \mathrm{GHz}$ active antenna employing a Y-Ba-Cu-O superconducting feedline and resonator stabilized oscillator has been demonstrated for the first time. The patch antenna and the hybrid oscillator were fabricated on scparate $\mathrm{LaAlO}_{3}$ substrates. The measurements on the antenna showed that it was $71 \%$ efficient at $77 \mathrm{~K}$ and $87.4 \%$ efficient at $30 \mathrm{~K}$. The oscillator had a maximum power of $11.5 \mathrm{dBm}$ and was $10.5 \%$ efficient at 


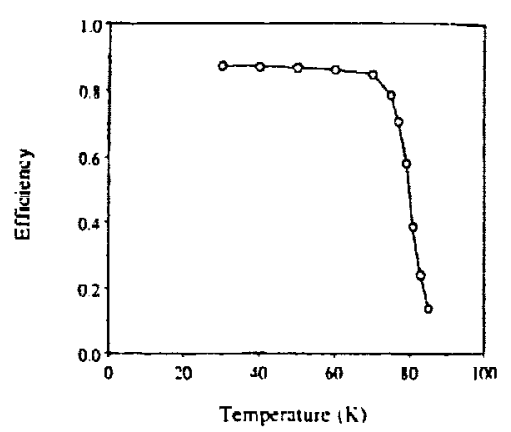

Fig. 4. Efficiency of the patch antenna as a function of semperature measured from $30 \mathrm{~K}$ to $85 \mathrm{~K}$. The efficiency at $77 \mathrm{~K}$ was $71 \%$.

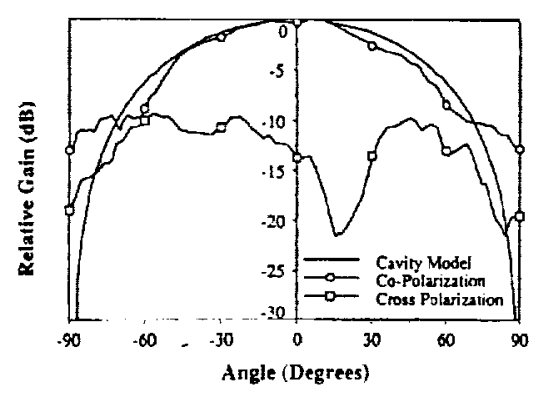

(a)

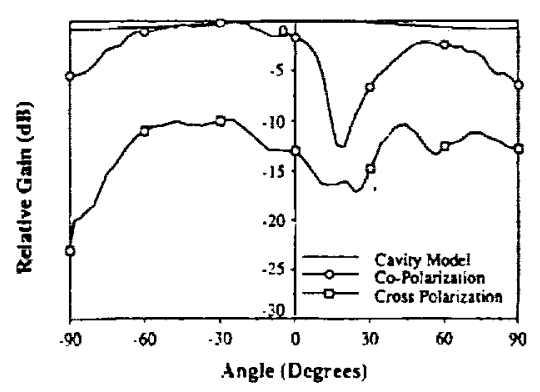

(b)

Fig. 5. Radiation patterns for the patch antenna at $77 \mathrm{~K}$ a) $H$-plane radiation patterns comparing the cavity model (solid line) with the co-polarization data (open circles) and also displaying the cross polarization data (open squares). b) $E$-plane radiation patterns comparing the cavity model with the co-polarizaton data and also displaying the cross polarizaton data.

$77 \mathrm{~K}$. The sensitivity of the frequency as a function of temperature was $-10 \mathrm{MHz} / \mathrm{K}$. The radiation patterns for the oscillator were measured as a function of the angle and compared to a cavity model for a driving power from the oscillator of $-2.0 \mathrm{dBm}$. The $H$-plane showed good agreement with the model, while interference due to the oscillator was present in each trace except the co-polarization of $H$-plane.

\section{ACKNOWLEDGMENTS}

The authors would like to thank Chris Chorey for his assistance in the testing of the transistor at cryogenic temperatures.

\section{REFERENCES}

[1] C. M. Chorey, K. Kong. K. B. Bhasin, J. D. Warner, and T. Joh, "YBCO Superconducting ring resonator at millimeter-wave frequencics," IEEE Trans. Wicresace Theon' Tech., vol. 39, no. 9. pp. 1480-1487, Sept. 1991.

[2] J, H. Takemolo, F. K. Oshita. II. R. Fetterman, P. Korbin, and E. Sovoro, "Microstrip ring resonator technique for measuring microwave attenuation in high- $T_{c}$ supcrconducting thin films," IEEE Tran.s. Microwace Theory Tech., vol. 37, pp. 1650-1652, 1989.

[3] W. G. Lyons, R. R. Bonetti, A. E. Williams, P. M. Mankiewich. M. L. O'Malley, J. M. Hamm, A. C. Anderson, R. S. Withers, A. Meulenberg, and R. E. Howard, "High- $T_{\mathrm{c}}$ superconductive microwave filters," JEEE Trans. Magn., vol. 27, no. 2, pp. 2537-2539, Mar. 1991

[4] E. B. Ekhoim and S. W. McKnight, "Attenuation and dispersion for high- $T_{c}$ superconducting microstrip lines," IEEE Trass. Microware Theory Tech., vol. 38, no. 4, pp. 387-395, Apr. 1990.

[5] M. A. Richard, K. B. Bhasin, C. Gilbert, S. Metzler, G. Keopf, and P. C. Claspy, "Performance of a four-element Ka-band hightemperature superconducting microstrip antenna," IEEE Microwaic Guided Waie Letl., vol. 2, no. 4, pp. 143-145, Apr. 1992.

[6] R. J. Dinger, "Some potential antenna applications of high temperature superconductors," J. Superconduct, vol. 3, no. 3, pp. $287-196,1990$.

[7] R. C. Hansen, "Superconducting antennas," IEEE Trans. Aerospace Electronic Syst., vol. 26, no. 2, pp. 345-354, Mar. 1990.

[8] N. J. Rohrer, G. J. Valco, and K. B. Bhasin, "Hybrid high temperature superconductor/GaAs $10 \mathrm{GHz}$ microwave oscillator: Temperature and bias effects," IEEE Trans. Microwaze Theory Tech, (Acceptcd for publication).

[9] W. C. Chew and J. A. Kong, "Effects of fringing fields on the capacitance of circular microstrip disks," IEEE Trans. Microwace Theory Tech., vol. 28, no. 2, pp. 98-104, Feb. 1990.

[10] J. D. Warner, K. B. Bhasin, N. J. Varljay, D. Y. Bowman, and C. M. Chorey, "Growth and patterning of laser ablated superconducting YBCO films on LaAIO3 substrates," NASA Report No. TM-102336.

[11] H. A. Wheeler, "The radiansphere around a small antenna," Proc. IRE, vol. 47, pp. 1325-1331, Aug. 1959.

[12] I. J. Bhal and P. Bhartia, Microstrip Antennas, Massachusetts: Arrech House, 1980.

[13] D. H. Schaubert and K. S. Yngvesson, "Experimental study of a microstrip array on high permittivity substrate," IEEE Trans. Amennas Propag., vol. 34, no. 1, pp. 92-97, Jan. 1986.

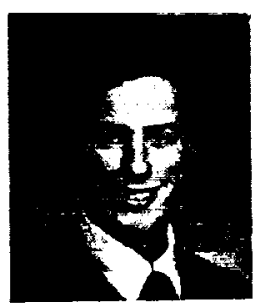

Norman J. Rohrer received the B.S. degree in physics and mathematics from Manchester College, North Manchester, Indiana in 1987, and the M.S. and Ph.D. degrees in electrical engineering from the Ohio State University, Columbus, Ohio, in 1990 and 1992, respecrively.

As a graduate student, he was recipient of a NASA Graduate Student Rescarch Fellowship under which he was able to complete his dissertation research on superconducting microwave oscillators. Since August of 1992, he has been employed by IBM, Burlington, Vermont. in the Technology Products Division.

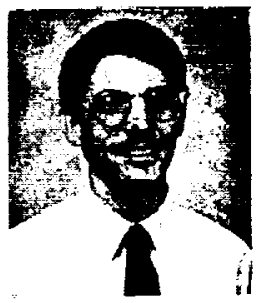

M. A. Richard (5*92) received the B.A. in physics from Bluffton College in 1988 and the M.S. and Ph.D. degrees in electrical engineering from Case Wesiern Reserve University in 1990 and January, 1993, respectively.

He was a recipient of an Ohio Aerospace Institute /NASA Spalce Grant Docroral Fellowship. Dr. Richard has co-authored 15 technical papers, one of which won first place at the IEEE Antennas and Propagation Society's 1992 Siudent Paper Contest. He is currenly it Research 
Associate at Case Western Reserve University where he is continuing his investigation of superconducting anternas.

George J. Valco (M'B6) received the B.S. and M.S. degrees in electrical engineering from Case Western Reserve University in 1979 and 1981, respectively. He received the Ph.D. in elcctrical engineering from the University of Cincinnati in 1986.

In 1986 he joined the faculty of the Ohio State University where he is currently an assistant professor of electrical engineering. His current research interests are electronic applications of high temperature superconductors, electronic properties of diamond films, photovoltaics, and compound semiconductor devices and technology.
Kul B. Bhasin (S74-M'83-SM'89) reccived the M.S. and Ph.D. degrees from Purdue University and the University of Missouri-Rulla, respectively.

Since 1983 he has been a senior rescarch scientist in the Solid State Technology Branch of the Space Electronics Division of the NASA Lewis Research Center in Cleveland. Ohio. Prior to joining NASA he was with Gould, Inc. from 1977 to 1983 as senior scientist and manager of technology. He is currently engaged in derclopment of GaAs microwave devices and circuits, microwave photonics and superconducting electronics for space applications. He has authored many publications and co-edited the book, Microwate Integrated Circuits. He is the recipien of the IR-100 Award, the NASA Group Achievement Awards, the Gould Scientific Achievement Award and is on the editorial board of $\mathrm{Mi}$. crowave and Optical Technology Letters. He is a member of APS, Sigma $\mathrm{Xi}$, and a member of the Fellow International Society for Optical Engineers. 



\title{
PERFORMANCE OF TICaBaCuO $30 \mathrm{GHZ} 64$ ELEMENT ANTENNA ARRAY
}

\author{
L. L. Lewis and G. Koepf \\ Ball Communications Systems Division, \\ Broom/ield, CO 80038-1235 \\ K. B. Bhasin \\ NASA Lewis Research Center, \\ Cleveland, $\mathrm{OH} 44135$ \\ M. A. Richard \\ Case Westem Reserve University, \\ Cleveland, $\mathrm{OH} 44106$
}

\begin{abstract}
A 64 element, $30 \mathrm{GHz}$, microstrip antenna array with corporate feed nctwork was designed and built on $2.254 \mathrm{~mm}$ (10 mil) thick lanthanum aluminate substrate. One antenna pattern was fabricated from gold film, and a second pattern used $\mathrm{TC} \mathrm{CaBaCuO}$ bigh temperature superconductor. Both antennas used gold ground planes deposited on the reverse side of the substrate. Gain and radiation patterns were measured for both antennas at room temperature and at cryogenic temperatures. Observations agree well with simple models for loss and microwave beam width, with a gain on boresight of $20.3 \mathrm{~dB}$ and beam width of 15 degrees for the superconducting antenna.
\end{abstract}

\section{INTRODUCTION}

When microstrip antenna design [1] is extended to microwave frequencies above $30 \mathrm{GHz}$.certain difficulties become apparent. Losses due to surface waves [2] and radiation [3] become more significant than at lower frequencies. Both of these losses may be reduced by decreasing the thickness of the substrate, drawing the ground plane closer to the microstrip traces. However, the trace widths must also be reduced in order to maintain a given transmission line impedance. The narrower lines have high resistive losses when conventional metals are used to form the traces. For copper traces on a $.152 \mathrm{~mm}(6 \mathrm{mil})$ thick sapphire substrate, for example, a $30 \mathrm{GHz}$ phased array with $40 \mathrm{~dB}$ directivity will have more than $25 \mathrm{~dB}$ of loss [4]. In order to reduce these resistive losses, high temperature superconducting (HTS) materials may be used to form the feed networks for high gain phased array antennas [5]. When a high quality HTS film on $.254 \mathrm{~mm}$ (10 mil) lanthanum aluminate (LAO) is used instead of copper for a $30 \mathrm{GHz}$ anterna of $40 \mathrm{~dB}$ directivity, the loss is only $3 \mathrm{~dB}$ [4]. This paper describes the design, construction, and performance of the first $30 \mathrm{GHz}, 64$ element phased array antenna that uses an HTS feed network. The successful implementation of HTS circuits with this relatively low gain antenna supports the position that high gain millimeter wave antennas would benefit from use of the new superconductors.

Manuscript received August 24, 1992. Research supported in part by NASA Headquarters, Satellite Communications Applications Research (SCAR) Program.

\section{ANTENNA DESIGN}

\section{A. General Design}

For ease in fabrication, and in order to compare HTS performance with copper performance, we selected an array design with 64 rectangular patches arranged in an $8 \times 8$ square pattern (Fig. 1). Element spacing was $4500 \mu \mathrm{m}$, which is slightly less than one-half of the free space wavelength. This reduced spacing allowed us to place the entire array on a $50.8 \mathrm{~mm}$ ( 2 inch) diameter wafer of LAO, without appreciably changing the radiation pattern of the antenna. Wafer thickness pas chosen to be $.254 \mathrm{~mm}(10$ mils), with a gold ground plane on the reverse side. The corporate feed network uses $50 \mathrm{ohm}$ lines, which are split to the patch elements by means of six levels of quarter wave -microstrip transformers. The relative dielectric constant of LAO is approximately 24 [6], which results in a microstrip line width of $92 \mu \mathrm{m}$ for this geometry.

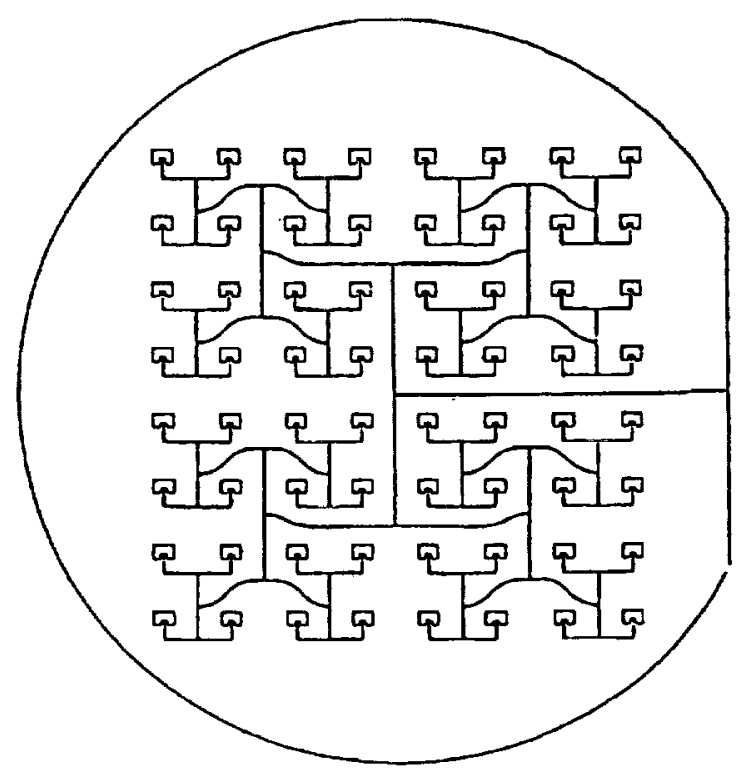

Fig. I Layout of patch elemenls and feed network for the $30 \mathrm{GHz}$ phased array antenna. Wafer diameter is $50.8 \mathrm{~mm}$ ( 2 inches).

(C) 1993 IEEE. Reprinted, with permission, from IEEE Transactions on Applied Superconductivity, vol. 3, no. 1, Mar. 1993, Pp. 2844-2847. 


\section{Antenna Patch Elements}

Because of the uncertainty in material properties and the upplication of microwave design rules for substratcs with grch k: gh dielectric constant, we designed, fabricated, and kested single patches at $15 \mathrm{GHz}$ first, in order to determine the validity of our models for devices on LAO at MOMW frequencies. We then extended the design to $30 \mathrm{GHz}$ patches, ntich were then used in anrays. The patches are rectangular, with width $W$ and length $L$ (Fig. 2). A microstrip line feeds directly to a notched input of depth $d$. The calculation of the pasch resonance frequency is not difficult, but an accurate calculation of patch impedance is nontrivial. We use a Mixed Potential Integral Equation (MPIE) approach [7]. This is one of several 'full wave' models, which should give good values for patch impedance, surface wave components, and radiation patterns. The patch impedance is needed in order to couple the microwave power efficiently into the patch. The antenna efficiency is determined in part by the resistive losses of the patch, and also by the energy lost to surface waves.

The edge impedance of a rectangular patch on LAO is very high, requiring the use of the notch, which allows coupiing near the center of the patch, where the impedance goes to zero. We select a point where the impedance is 100 ohms, and use a quarter wave transformer to match the 50 ohm input line to this point. Typical values are $W=3000 \mu \mathrm{m}$, $\mathrm{L}=2000 \cdot \mu \mathrm{m}$, and $\mathrm{d}=782 \mu \mathrm{m}$ for a resonance frequency of $14.84 \mathrm{GHz}$, and theoretical input impedance of $78 \mathrm{ohms}$. The measured impedance in this case was 72 ohms. For the 64 clement array, we used patches with $\mathrm{W}=1350 \mu \mathrm{m}, \mathrm{L}=900$ $\mu \mathrm{m}$, and $\mathrm{d}=337 \mu \mathrm{m}$. These elements have a predicted rescnance frequency of $31.25 \mathrm{GHz}$, and input impedance of 100 ohms.

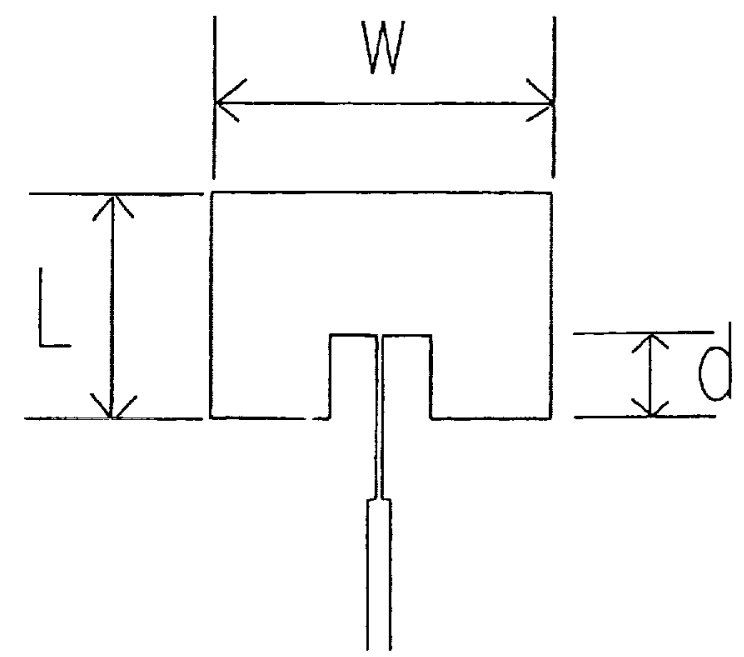

Fig. 2 Antenna patch element, showing quarter wave input transformer.

\section{C: Surface Waves}

The high dielectric constant of LAO means that even a $.254 \mathrm{~mm}$ (10 mil) substrate is electrically thick. While the cutorf frequency for propagation of the $T_{0}$ surface wave mode is about $60 \mathrm{GHz}$, the $\mathrm{TM}_{0}$ mode is supported at all frequencies. This can be a source of energy loss. We have calculated the radiation efficiency of a single patch, using an electric surface current model [8] to estimate the surface wave losses. At $15 \mathrm{GHz}$, the single patch efficiency is about $8+$ percent. At $30 \mathrm{GHz}$, the efficiency drops to about 60 percent.

In theory, the efficiency of an array can be improved considerably over this value by carefully placing the radiating elements at the correct distance aparh so that the surface wave components destructively interfere. The spacing can also be chosen so that the spatial part of the radiation constructively interferes. Both are possible at the same time because the wavelength of the surface waves is nearly one fifth of the free space wavelength. In practice, however, the presence of the feed network makes it difficult to predict the exact propagation constants in the structure, so that surface waves can be suppressed.

\section{FABRICATION}

The preliminary single patches at $15 \mathrm{GHz}$ and $30 \mathrm{GHz}$ were fabricated at Ball using $4 \mu \mathrm{m}$ thick gold on $.254 \mathrm{~mm}$ (10 mil) thick LAO, with a titanium adhesion layer. Both plate up and etch down processes were used. Gold ground planes were deposited on the reverse side of the LAO. The diced patches were soldered with indium to gold plated metal carriers made of Alloy 48, which matches the coefficient of thermal expansion of the LAO. The carriers were then mounted in a test fixture, using gold ribbon bonds to microstrip launchers, which in turn were bonded to 'V-type' microwave connectors.

The 64 element array was patterned by Superconductor Technologies, Inc. on a $50.8 \mathrm{~mm}$ ( 2 inch) diameter, $.254 \mathrm{~mm}$ (10 mil) thick LAO. One array was formed with $3 \mu \mathrm{m}$ thick gold film, using a titanium-tungsten adhesion layer, and a second array was formed with $\pi_{2} \mathrm{CaBa}_{2} \mathrm{Cu}_{2} \mathrm{O}_{8}$ high temperature superconductor. Both arrays used a gold ground plane deposited on the reverse side of the LAO. The $50 \mathrm{ohm}$ microstrip feed line, as shown in Fig. 1, passes to the edge of the wafer, where a gold ribbon bond is made to a microstrip launcher. In the case of the HTS array, a gold contact strip is deposited over the superconductor near the end of the swafer, for bonding purposes. As with the single patches, the wafer is soldered to a gold plated fixture using an indium alloy. On both the gold and the HTS arrays, line widehs were held to a tolerance of about $3 \mu \mathrm{m}$. Substrate thickness variations were less than $.025 \mathrm{~mm}$ (1 mil). 


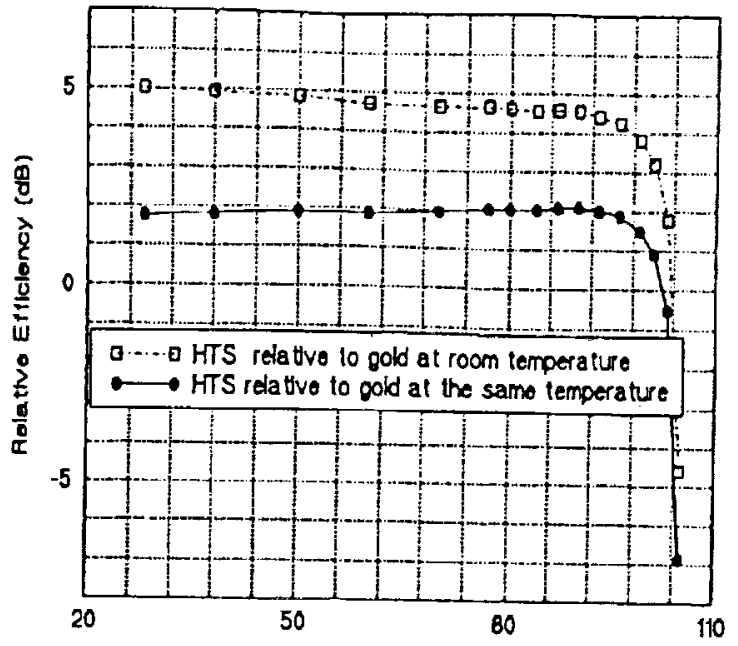

Fig. 3 Efficlency of HTS anteme rela the to gold entenna.

\section{PERFORMANCE}

The resonance frequency of both the gold and the HTS arrays was measured at Ball, at both room temperature and liquid nitrogen temperatures. The gold array was resonant at $30.7 \mathrm{GHz}$ (room temperature) and $31.1 \mathrm{GHz}(77 \mathrm{~K})$. The HTS array was resonant at $30.55 \mathrm{GHz}(77 \mathrm{~K})$. A calibrated gain measurement of the gold array was made at Ball, at room temperature. The measured gain, on resonance and on boresight was $15.6 \mathrm{dBil}$ ( $\mathrm{H}$-plane). The $3 \mathrm{~dB}$ beam width was 13 degrees. The relative gain of the gold and HTS antennas at cryogenic temperatures was then measured at NASA Lewis Research Center. We express the normalized gain, $G$, of an antenna in terms of the usual $S$ parameters:

$$
G=\frac{\left|S_{21}\right|^{2}}{1-\left|S_{11}\right|^{2}}
$$

(1)

Then the efficiency of the HTS antenna relative to the gold antenna is just

$$
\varepsilon_{h T S-A y}=G_{h T S} / G_{A y}
$$

Fig. 3 gives the efficiency of the HTS antenna relative to the gold antenna at $300 \mathrm{~K}$ and also relative to the gold anterna at the same temperature as the HTS antenna. At $77 \mathrm{~K}$, the HTS antenna is $4.7 \mathrm{~dB}$ higher gain than the gold antenna at room temperature. We therefore conclude, using the calibrated gain measurements of the gold antenna, that the gain of the HTS antenna at $77 \mathrm{~K}$ is $20.3 \mathrm{dBi}$. This is to be compared with the maximum possible gain (no losses) of $22.2 \mathrm{dBi}$. The inferred loss of $1.9 \mathrm{~dB}$ can easily be attributed to losses in the microwave connectors, gold ground plane, and surface waves. Indeed, the predicted maximum loss due to surface waves alone is $2.2 \mathrm{~dB}$. Using a simple model of resistive losses in the feed network, we expect the gold antenna losses at $300 \mathrm{~K}$ to be $3.8 \mathrm{~dB}$, and $2.2 \mathrm{~dB}$ at $77 \mathrm{~K}$. Similarly, we expect the HTS losses to be $4 \mathrm{~dB}$ at $77 \mathrm{~K}$. The measured gains are in reasonable agreement with these estimates.

Fig. 4 and Fig. 5 give the E-plane and H-plane radiation pattem measurements for the HTS antenna at $77 \mathrm{~K}$. These two measurements are in excellent agreement with the predicted patterns, showing the first side lobes at $-13 \mathrm{dBc}$, with good symmetry. The slight skewing of the central lobe may be attributed to asymmetry in the measurement fixture.

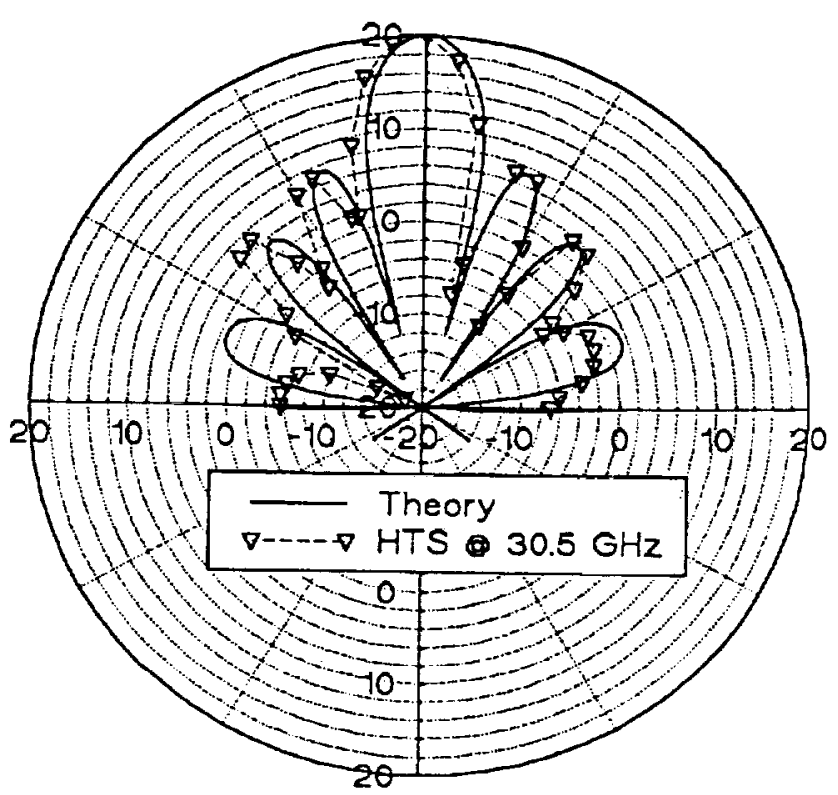

Fig. 4 E-plane radiation pattem, normalized to $20 \mathrm{~dB}$. 
[5] M. A. Richard, K. B. Bhasin, C. Gilbert, S. Metzler, and P. C. Claspy, "Measurement techniques for cryogenic Ka-Band microstrip antennas," Antenna

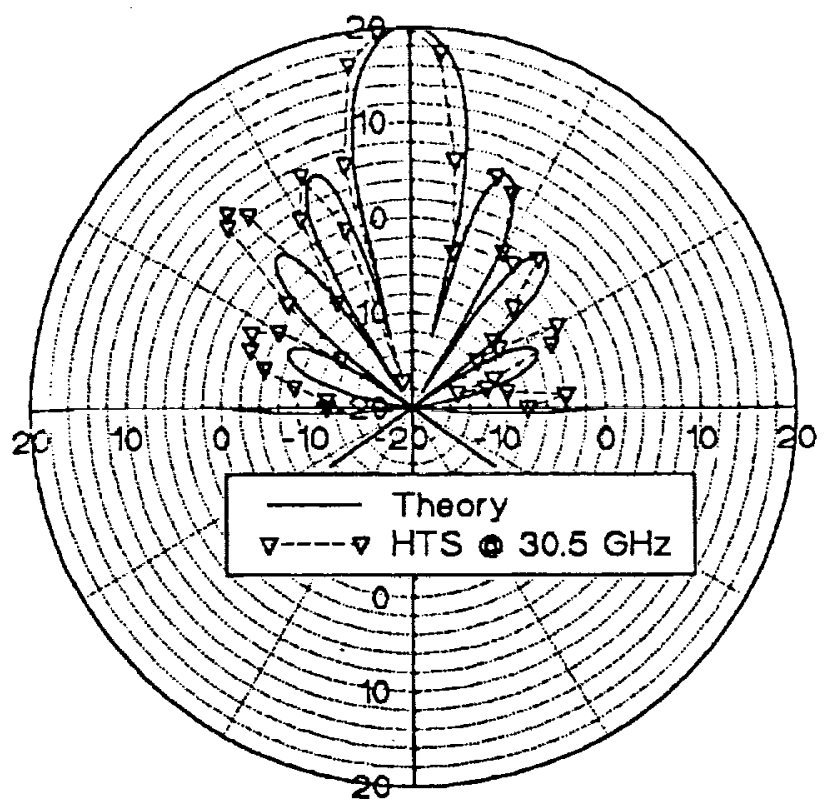
Measurement Tech. Association Proc., pp. 1.13$1.17,1991$.

[6] Tsuneo Konaka, Makoto Sato, Hidefumi Asano, and Shugo Kubo, "Relative Permitivity and Dielectric Loss Tangent of Substrate Materials for High- $T_{c}$ Superconducting Film," Journal of Superconductivity, Vol. 4, No. 4, pp. 283-288, 1991.

[7] J. R. Mosig, "Arbitrarily Shaped Microstrip Structures and their Analysis with a Mixed Potential Integral Equation," IEEE Trans. Microwave Theory and Techniques, Vol. 36, No. 2, pp. 314-323, February 1988.

[8] P. Perlmutter, S. Shtrikman, and D. Treves, "Electric Surface Current Model for the Analysis of Microstrip Antennas with Application to Rectangular Elements," IEEE Transactions on Antennas and Propagation, Vol. AP-33, No. 3, pp. 301-311, March 1985.

Fig. 5 H-plane radiation pattern, normalized to $20 \mathrm{~dB}$.

\section{SUMMARY}

The measured performance of a $30 \mathrm{GHz}, 64$ element phased array antenna with a superconducting feed network agrees well with theory. The antenna loss is only $1.9 \mathrm{~dB}$, and the radiation patterns behave as predicted. These results support the contention that significant gain improvernents are possible in a high gain millimeter wave antenna that uses an HTS feed network.

\section{REFERENCES}

[1] P. Bhartia, K. V. S. Rao, and R. S. Tomar, Millimeter-Wove Microstrip and Printed Circuit Antennas, Boston: Artech House, 1991, 322 pp.

[2] Pisti B. Kaiehi and Nicolaos G. Alexopoulos, "On the Effect of Substrate Thickness and Permittivity on Printed Circuit Dipole Properties," IEEE Trans. on Antennas and Propagation, Vol. AP-31, No. 1, pp. 34-39, January, 1983.

[3] L. Lewin, "Radiation from Discontinuities in Stripline," IEEE Monograph No. 358E, Febraary 1960.

[4] Fred Schmidt, "Superconducting Antennas Applications and Architecture Study," Final Report, NASA contract No. NASW-4514, August, 1991, pp. 49-53. 